\title{
A EXTENSÃO UNIVERSITÁRIA PROMOVENDO REFLEXÕES SOBRE AS TRANSFORMAÇÕES NA EDUCAÇÃO PÚBLICA: AÇÕES DO PROGRAMA PENSAR A EDUCAÇÃO, PENSAR O BRASIL - 1822-20221
}

University outreach promoting reflections on changes in public education:

Pensar a Educação, Pensar o Brasil - 1822-2022 program actions

Hercules Pimenta dos Santos ${ }^{2}$

\begin{abstract}
RESUMO
Entendendo a importância de se refletir sobre o papel da universidade pública por meio da sua produção de conhecimento e da responsabilidade de integrar esta produção socialmente, sentimos a necessidade de pensar esta produção sob uma perspectiva de integração, o que pressupõe uma ação interdisciplinar. Apresentamos neste trabalho uma ação que vem buscando criar e desenvolver projetos voltados para o público em geral, utilizando para isto diversas mídias, visando qualificar e expandir a reflexão acerca do tema Educação Pública. O objetivo deste artigo é apresentar à comunidade acadêmica as diversas e diversificadas ações do programa Pensar a Educação Pensar o Brasil 1822-2022, procurando demonstrar como estamos potencializando o princípio, que consideramos fundamental na atividade universitária, da indissociável relação das atividades de extensão com o ensino e a produção acadêmica do conhecimento. Objetivamos oportunizar aqui reflexões sobre a formação e o aperfeiçoamento de competências dos atores educacionais envolvidos neste programa de ações.
\end{abstract}

Palavras-chave: educação; escola pública; interdisciplinaridade; responsabilidade social; extensão universitária.

\begin{abstract}
Understanding the importance of reflecting on the role of public universities through their production of knowledge and responsibility to socially integrate this production, we feel the need to think this production from the perspective of integration, which requires interdisciplinary actions. In this work we describe an action that seeks to create and develop projects for the general public using various media for this in order to qualify and expand the discussion on the Public Education subject. The objective of this paper is to present to the academic community the diverse actions of the program Pensar a

\footnotetext{
${ }^{1}$ Projeto financiado pela Fundação de Amparo a Pesquisa de Minas Gerais (FAPEMIG).

2 Mestrando em Educação pelo PPGE/FaE-UFMG; Especialização em Planejamento, Implementação e Gestão da Educação à Distância pela Universidade Federal Fluminense (Lante-UFF); professor na pósgraduação e cursos de extensão da Faculdades Milton Campos (FMC-MG). E-mail: herculessantos.ufmg@gmail.com.
}

SANTOS, Hercules P. A extensão universitária promovendo reflexões sobre as transformações na educação pública: ações do Programa Pensar a Educação, Pensar o Brasil - 1822-2022. Extensão em Foco, Curitiba: Ed. da UFPR, nr.9, jan/jun 2014, p.130145. ISSN 2358-7180. 
Educação, Pensar o Brasil - 1822-2022, trying to demonstrate how we are leveraging that principle which we consider essential in university activities, about the inseparable relationship of university outreach practices to teaching and academic knowledge development. Here we intended to offer reflections on the formation and improvement of skills of the educational actors involved in this action program.

Keywords: education; public schools; interdisciplinarity; social responsibility; university outreach.

Entendendo que a Educação é uma das faces mais presentes dentre as oito áreas ${ }^{3}$ da extensão universitária, nos voltamos para estas ações no interior da universidade pública visualizando o seu caráter formador. Estudantes de diferentes áreas, envolvidos com temáticas diversificadas, são contemplados com a oportunidade de aproximação com realidades diversas, demandas e movimentos sociais; um contato mais estreito com as necessidades de produção do conhecimento, que deve ser revertido para uma melhor concepção e qualificação social da humanidade. Neste sentido, de um processo educativo, a Extensão Universitária abrange ações frente às demais áreas de sua atuação propiciando criar propostas interdisciplinares que permitem experimentações metodológicas, além da possibilidade de identificar empiricamente novos problemas para estudos e pesquisas.

O Programa de Ensino, Pesquisa e Extensão Pensar a Educação Pensar o Brasil 1822-2022 (PEPB), vem sendo desenvolvido desde o ano de 2007, articulando projetos em torno do tema Educação Pública. Os coordenadores deste programa, desde a sua concepção, são os professores Luciano Mendes de Faria Filho da Faculdade de Educação da UFMG e Tarcísio Mauro Vago da Escola de Educação Física da UFMG. Suas ações são desenvolvidas por um grupo multidisciplinar de professores e alunos, dos níveis de graduação, mestrado, doutorado e pós-doutorado da Universidade Federal de Minas Gerais (UFMG), que atuam em diferentes áreas do conhecimento, bem como Pedagogia, Educação Física, História, Letras e Comunicação

\footnotetext{
3 A prática do pensamento e da extensão universitária brasileira delineou-se nos fóruns nacionais de extensão universitária na década de 1990 e devem ser classificadas em uma das oito áreas temáticas definidas pelo Plano Nacional de Extensão Universitária (FORPROEX, 2001): Comunicação, Cultura, Direitos Humanos e Justiça, Educação, Meio Ambiente, Saúde, Tecnologia e Produção e Trabalho.
}

SANTOS, Hercules P. A extensão universitária promovendo reflexões sobre as transformações na educação pública: ações do Programa Pensar a Educação, Pensar o Brasil - 1822-2022. Extensão em Foco, Curitiba: Ed. da UFPR, nr.9, jan/jun 2014, p.130145. ISSN 2358-7180. 
Social, em sua maioria, vinculadas ao Grupo Estudos de Pesquisas em História da Educação da Faculdade de Educação da UFMG (GEPHE).

Acreditamos ser importante refletir sobre o papel da universidade pública, sua produção do conhecimento e a responsabilidade de integrar esta produção socialmente. É necessário pensar a produção do conhecimento em uma perspectiva de integração, o que pressupõe uma ação interdisciplinar. Uma interdisciplinaridade que não pretende unificar os saberes, mas deseja a mediação entre conhecimentos e a articulação destes saberes, com suas disciplinas em situação de coordenação e cooperação para a construção de um termo conceitual e metodológico capaz de facilitar a compreensão de realidades complexas. O objetivo interdisciplinar não é unificar disciplinas, mas sim estabelecer vinculações entre elas, construindo referências conceituais e metodológicas consensuais, promovendo diálogos e trocas entre campos disciplinares.

Nossas ações no referido programa vêm buscando criar e desenvolver projetos voltados para o público em geral, mas principalmente para os professores em formação e exercício, utilizando para isto diversas mídias, visando qualificar e expandir a reflexão acerca do tema Educação Pública. Atribuímos grande valor ao caráter formativo dos envolvidos nestas ações, propiciando desenvolvimento contínuo e dinâmico das competências construídas no percurso, favorecendo a consciência da necessidade de redimensionar, ou não, as ações pedagógicas e culturais ao longo do seu processo.

Objetivamos oportunizar reflexões sobre a formação e 0 aperfeiçoamento de competências dos atores educacionais envolvidos neste programa. Queremos potencializar o princípio que consideramos fundamental na atividade universitária - a indissociável relação das atividades de extensão com o ensino e a produção acadêmica do conhecimento.

O que pensamos estar buscando é cumprir com a responsabilidade social da Universidade Pública na produção e divulgação do conhecimento. Trata-se de retomar a ideia de que a função da universidade é produzir conhecimento e ser o espaço da crítica qualificada, e não o de operacionalizar

SANTOS, Hercules P. A extensão universitária promovendo reflexões sobre as transformações na educação pública: ações do Programa Pensar a Educação, Pensar o Brasil - 1822-2022. Extensão em Foco, Curitiba: Ed. da UFPR, nr.9, jan/jun 2014, p.130145. ISSN 2358-7180. 
as políticas públicas, estatais ou não. É neste sentido que assumimos a extensão universitária como um princípio fundamental de formação diferenciada do estudante e da possibilidade de produzir novas pesquisas derivadas da relação da universidade com a sociedade. Esta é uma forma transformadora, representando uma das expressões das atribuições sociais da universidade, que deve ser a produção de um conhecimento de relevância social, suscitador de transformações de efeito concreto por serem demandadas pelos extratos sociais envolvidos.

\section{Pensar a Educação Pensar o Brasil 1822-2022}

Procuramos aproveitar o período que antecede às comemorações dos 200 anos da Independência do Brasil, a ser completado no ano de 2022, para propor ações que estimulem a reflexão sobre a contribuição da Educação para a construção de um país mais justo e igualitário. Nós, integrantes deste programa, acreditamos que a Educação, como um direito social, é uma das principais ferramentas para a formação de cidadãos conscientes de seus direitos e deveres e de um maior protagonismo no processo democrático.

De acordo com as palavras do principal idealizador deste programa, Prof. Luciano Mendes de Faria Filho, "entendemos que uma das maneiras de projetar alternativas viáveis para a construção de um país mais democrático e igualitário é, justamente, o esforço para pensar os nossos problemas de maneira plural e diversificada, fugindo de lugares comuns e das soluções fáceis" (PENSAR A EDUCAÇÃO, 2007, p. 01). É baseado nestas ideias que queremos ampliar o espaço da reflexão crítica, pois entendemos ser este um imperativo nos dias atuais.

O professor Luciano Mendes observou que, motivado por escândalos políticos e por transformações de fundo pelas quais passava a esfera pública no Brasil e no mundo no ano de 2007, surgiram reflexões sobre o "silêncio dos intelectuais" e sobre o "esquecimento da política". Nessas reflexões, uma expressiva parcela da intelectualidade brasileira e internacional foi convidada a pensar sobre as transformações do espaço público e a participação política,

SANTOS, Hercules P. A extensão universitária promovendo reflexões sobre as transformações na educação pública: ações do Programa Pensar a Educação, Pensar o Brasil - 1822-2022. Extensão em Foco, Curitiba: Ed. da UFPR, nr.9, jan/jun 2014, p.130145. ISSN 2358-7180. 
nas últimas décadas, no mundo ocidental. Em suas palavras, nesse movimento houve, por assim dizer,

\begin{abstract}
Um esquecimento da escola pública no debate público dos intelectuais brasileiros sobre a democracia, a esfera pública e a participação política. É como se, infelizmente, nossa intelectualidade estivesse acreditando que é possível construir uma sociedade democrática sem o concurso de uma escola pública de qualidade. (PENSAR A EDUCAÇÃO, 2012, p. 01).
\end{abstract}

Dessa forma, as preocupações do professor Luciano Mendes giraram em torno de ressaltar que esta questão nem sempre foi assim. Ou seja, nem sempre os intelectuais brasileiros estiveram tão pouco preocupados com a escola pública que não seja a de nível superior.

Durante muito tempo, sobretudo a partir da independência, significativos setores da intelectualidade do nosso país estiveram convencidos da importância da democratização da escola como um índice de democratização da sociedade e como condição do aprendizado de uma cultura de política pública. Pode-se citar, como exemplo, a Educação passando a ter um contorno distinto do preconizado na antiga República, quando em 1924 foi criada a Associação Brasileira de Educação (A.B.E.), congregando intelectuais de diversas áreas, como advogados, engenheiros, médicos e professores, esses "desiludidos com a República e convencidos de que na educação residia a solução dos problemas do país" (CARVALHO, 1997, p. 115). A educação no âmbito da A.B.E. adquiriu um discurso cívico, um amplo movimento político, em torno de um programa de construção da nacionalidade.

Àquela época, no ano de 2007, Luciano Mendes questionou o significado do esquecimento da escola pública pelos intelectuais brasileiros. Segundo suas indagações, porque não houve tanta preocupação com as circunstâncias da escola pública, mesmo quando se discutia as condições de possibilidade de fortalecimento da democracia? Seria por acreditar que a democracia brasileira prescinde da escola de qualidade para todos? "Será porque, definitivamente no Brasil, a escola pública foi abandonada pela classe média, estrado de onde vem a maioria dos intelectuais?" Por que a escola transformações na educação pública: ações do Programa Pensar a Educação, Pensar o Brasil - 1822-2022. Extensão em Foco, Curitiba: Ed. da UFPR, nr.9, jan/jun 2014, p.130145. ISSN 2358-7180. 
pública é "a escola dos outros já que a nossa escola, a dos nossos filhos e filhas, é a escola privada?' (PENSAR A EDUCAÇÃO, 2007, p. 02).

Este é um dos indícios de mais um dos grandes perigos que rondam a nossa já frágil democracia. Entendemos estar em uma fase de silêncio sobre a educação ou do esquecimento da escola pública por parte de nossos mais importantes intelectuais. Para que possamos realizar uma crítica a estas posições e, ao mesmo tempo, abrir espaço para alternativas, é preciso alargar e ocupar, como intelectuais da educação, o espaço do debate público sobre a escola pública no Brasil. A situação se agrava quando notamos que o debate público nos dias atuais, além de restrito, está pautado por jornalistas e por técnicos de organismos nacionais e internacionais; não negamos que boa parte deles sejam bem intencionada, mas estes não tratam da educação com a profundidade que esta questão vem demandando.

Um dos fatores mais notáveis é que uma vez realizada a expansão da escola básica, a demanda, hoje, passou para a elevação da sua qualidade. Como analisa Faria Filho:

Desta dependeria, segundo os empresários, a mão de obra qualificada para fazer frente ao crescimento econômico; já segundo os cientistas, sem melhorar a educação básica não será possível suportar a crescente demanda por produção científica e tecnológica; sem melhorar a educação, afirmam as autoridades do estado, não será possível retirar o País da posição vergonhosa que ocupa nos rankings internacionais da educação; mas, também, sem melhor educação, dizem os ativistas sociais, não será possível fazer do Brasil um país de instituições modernas e mais democrático. Isto para listar apenas quatro dos principais argumentos mobilizados no momento. (FARIA FILHO, 2012).

Para realizar uma crítica a estas posições e, ao mesmo tempo, abrir espaço para alternativas, temos procurado alargar e ocupar, como intelectuais da educação, o espaço do debate público sobre a escola pública no Brasil. É por meio da atividade de extensão universitária que pretendemos potencializar o alcance e a divulgação de tal tarefa. Detalhamos a seguir as ações e os

SANTOS, Hercules P. A extensão universitária promovendo reflexões sobre as transformações na educação pública: ações do Programa Pensar a Educação, Pensar o Brasil - 1822-2022. Extensão em Foco, Curitiba: Ed. da UFPR, nr.9, jan/jun 2014, p.130145. ISSN 2358-7180. 
produtos realizados no âmbito do Programa de ensino, pesquisa e extensão Pensar a Educação, Pensar o Brasil 1822-2022.

\section{O Programa Pensar a Educação, Pensar o Brasil 1822-2022 é organizado por um conjunto de ações articuladas}

O primeiro projeto integrado ao programa Pensar a Educação Pensar o Brasil 1822-2022 foi o Seminário Anual. Realizado desde o ano de 2007, ele vem sendo organizado em oito conferências anuais, uma por mês, que giram em torno de um tema relevante para o debate sobre a educação pública. 0 público que participa das conferências é extenso, e muito diverso, compreendendo em sua grande maioria os professores das redes públicas de ensino municipal, estadual e federal, dos níveis básico e superior, além dos alunos e professores das instituições privadas de ensino. A temática trabalhada em nosso primeiro seminário anual teve como título Os intelectuais e o debate público sobre educação no Brasil. Para o ano de 2012, trazemos ao público discussões centralizadas sob o título: BRASIL: Que educação? Para que país?

As conferências são proferidas por importantes pesquisadores da UFMG e de outras instituições brasileiras. Temos procedido com a gravação em vídeo das palestras e a disponibilização em DVD, gratuitamente, para as pessoas interessadas. As palestras são gratuitas, com emissão de certificado e abertas à participação do público em geral. Para os alunos dos cursos superiores de graduação das instituições públicas e privadas, além do contato com a rica discussão sobre o tema Educação Pública, é também um momento importante para suas atividades acadêmicas, servindo como Atividade Complementar de Curso (ACC). Como modalidade disciplinar, as palestras integram o currículo do Programa de Pós-graduação da Faculdade de Educação da UFMG (PPGEFaE/UFMG), admitindo, além dos alunos regularmente matriculados nos cursos de mestrado e doutorado em Educação e de outros cursos da UFMG, em caráter de optativa, o ingresso de pessoas graduadas em qualquer instituição de ensino superior, na condição de disciplina isolada. Neste último caso, uma ótima oportunidade para a iniciação à pós-graduação.

SANTOS, Hercules P. A extensão universitária promovendo reflexões sobre as transformações na educação pública: ações do Programa Pensar a Educação, Pensar o Brasil - 1822-2022. Extensão em Foco, Curitiba: Ed. da UFPR, nr.9, jan/jun 2014, p.130145. ISSN 2358-7180. 
Acreditamos que as ACC proporcionam uma sistematização de conhecimentos incorporados de forma duradoura à formação dos graduandos, incentiva-os a procurar por ambientes culturalmente ricos e diversificados. Tal atividade é importante para a futura atuação profissional deste público por ser capaz de oferecer uma maior compreensão da realidade de vários grupos, seus saberes e manifestações culturais. Essa formação é ressaltada nas atividades extensionistas, promovendo a aproximação entre docentes, discentes e a comunidade em geral. Ao se integrar ensino e extensão, rompem-se os limites tradicionais da formação profissional multiplicando os espaços das práticas educativas.

Empenhamo-nos, sempre, em transmitir as palestras ao vivo também pela Internet, via rádio $W_{e b F a e}^{4}$, uma ação coordenada pelo professor Wemerson de Amorim da Faculdade de Educação da UFMG. A concepção deste veículo de comunicação começou a ser desenhada durante a greve dos professores das Instituições Federais de Ensino Superior (IFES) no ano de 2001, diante da experiência da Rádio Comunitária União - transmitida na Internet pela ONGNET ${ }^{5}$ - a qual cobriu diversos debates e eventos culturais que foram realizados na Praça de Serviços da UFMG, amplificando, naquele decisivo momento, tanto o alcance das discussões quanto a sua interatividade. Surgiu na ocasião uma grande satisfação e vontade, entre professores, alunos e membros da comunidade acadêmica, de que se constituísse uma rádio universitária na UFMG. A ideia encontrou barreiras em questões de diversas ordens, levando com o passar do tempo a se diluir e perder a força motivadora. Nesse meio tempo, o prof. Wemerson de Amorim, que foi um articulador ativo daquela retransmissão, tendo consigo uma longa atuação junto aos movimentos sociais e às rádios comunitárias, expressou o seu desejo de encontrar alternativas à transmissão radiofônica tradicional.

\footnotetext{
${ }^{4}$ Disponível em: <http://www.radio.fae.ufmg.br>.

5 ONGnet Brasil é uma associação, sem fins lucrativos, que tem por finalidade produzir e disseminar informações das entidades de movimentos sociais. Produz, agrega e difundi informações sobre as questões e temas de interesse para os indivíduos e as organizações da sociedade civil, sobre democratização da informação e dos meios de comunicação, mídia e movimentos sociais, educação, programas de geração do trabalho e renda, cultura, esporte, etnia, gênero, saneamento, ações de prevenção e tratamento de saúde, habitação, população em situação de risco, assim como fomenta estudos e pesquisas.
}

SANTOS, Hercules P. A extensão universitária promovendo reflexões sobre as transformações na educação pública: ações do Programa Pensar a Educação, Pensar o Brasil - 1822-2022. Extensão em Foco, Curitiba: Ed. da UFPR, nr.9, jan/jun 2014, p.130145. ISSN 2358-7180. 
Decidiu-se tentar, em caráter piloto e experimental, uma rádio baseada na Internet, escapando-se da pressão das políticas de concessão que o governo pratica junto às rádios comunitárias e dos equipamentos demandados por uma rádio convencional. Melhor do que se livrar destes obstáculos é poder contar, nesta modalidade de transmissão, com um alcance global enviando seu sinal sob demanda, ponto a ponto, articulando a comunicação local (rádios comunitárias/livres) com 0 global (grandes redes). Partiu-se aqui da compreensão de que a cultura informacional, no contexto da sociedade contemporânea, por sua riqueza de informações, solicitações e estímulos, democratiza o acesso ao conhecimento, pois propicia uma relativa alteração no monopólio do saber e do poder da fala autorizada em diferentes contextos.

\section{Coleção PEPB: expandindo o debate por meio da produção científica}

O segundo projeto integrado ao programa é a publicação de livros que integram a Coleção Pensar a Educação Pensar o Brasil, uma parceria com a Mazza Edições, de Belo Horizonte. Trata-se de um material de significativa contribuição para o pensamento e para as práticas educativas. É uma produção portadora de representações e valores predominantes de períodos de uma sociedade que, simultaneamente à historiografia da educação e da teoria da história, permitem revisar intenções e projetos de construção e de formação social no Brasil. É um objeto que colocamos em circulação, como muito bem salienta Chartier (1990), como um veículo de circulação de ideias traduzindo valores e comportamentos que se desejou, fossem ensinados.

A Coleção está organizada em três séries. A primeira é a série Seminários, com livros que reúnem os textos das conferências proferidas no Seminário Anual. Seu primeiro título, lançado no ano de 2009, foi Intelectuais e escola pública no Brasil: séculos XIX e XX, contendo textos baseados nas palestras do primeiro ano do projeto, em 2007. A cada ano é preparado 0 lançamento de um novo livro desta série, contendo discussões realizadas por intelectuais da educação que são, em sua grande maioria, provenientes de

SANTOS, Hercules P. A extensão universitária promovendo reflexões sobre as transformações na educação pública: ações do Programa Pensar a Educação, Pensar o Brasil - 1822-2022. Extensão em Foco, Curitiba: Ed. da UFPR, nr.9, jan/jun 2014, p.130145. ISSN 2358-7180. 
várias universidades brasileiras, sendo estes os mesmos autores convidados a realizar as palestras nos seminários anuais.

A segunda série é a Clássicos da Educação Brasileira, cujo objetivo é o de contribuir para o estímulo à leitura e aproximar os clássicos da educação brasileira do público em geral, em especial, professores e professoras. Esta série é subdividida em volumes e já conta com dois lançamentos, volume 1, em 2010, e volume 2, em 2011.

A terceira série, Estudos Históricos, teve em sua primeira obra, lançada em 2009, o título Políticos, Literatos, Professoras, Intelectuais: O Debate Público sobre educação em Minas Gerais. A série Estudos Históricos visa dispor de trabalhos de história da educação, e de áreas afins, que contribuam para ampliar o entendimento sobre o lugar da educação no âmbito dos projetos do Brasil, delineados ao longo de nossa história. Estamos preparando o lançamento de outras publicações que compreenderão novas séries intituladas Diálogos e série Ensaios. A publicação de todas estas obras tem contado com o apoio financeiro, de fundamental importância, da Fundação de Amparo à Pesquisa do Estado de Minas Gerais (FAPEMIG).

\section{Um programa de rádio na Estação do Conhecimento}

O rádio é a escola dos que não têm escola, é o jornal de quem não sabe ler, é o mestre de quem não pode ir à escola, é o divertimento gratuito do pobre, é o animador de novas esperanças, o consolador dos enfermos e o guia dos sãos desde que o realizem com espírito altruísta e elevado, pela cultura dos que vivem em nossa terra, pelo progresso do Brasil.

Edgard Roquette-Pinto

O terceiro projeto integrado às ações de ensino, pesquisa e extensão é um programa radiofônico transmitido pela Rádio UFMG Educativa, 104,5 FM ${ }^{6}$. Esta emissora foi inaugurada, oficialmente, em setembro de 2005, pretendendo

\footnotetext{
${ }^{6}$ Acesse a Rádio UFMG Educativa pela Internet em: <http://www.ufmg.br/online/radio>.

SANTOS, Hercules P. A extensão universitária promovendo reflexões sobre as transformações na educação pública: ações do Programa Pensar a Educação, Pensar o Brasil - 1822-2022. Extensão em Foco, Curitiba: Ed. da UFPR, nr.9, jan/jun 2014, p.130145. ISSN 2358-7180.
} 
ser uma opção para os ouvintes da região metropolitana de Belo Horizonte, Minas Gerais. Sua programação é composta por programas jornalísticos, além de informar sobre o universo da Universidade. Seus ouvintes também têm acesso a notícias nacionais e locais com uma cobertura independente. A radiodifusão brasileira conta hoje com uma rede de emissoras bastante ampla, cobrindo todo o território nacional, de forma muito maior do que a própria televisão. São cerca de 3.000 emissoras, transmitindo em Ondas Curtas, AM e FM. Infelizmente, deste total, menos de 5\% são emissoras educativas.

O programa de rádio Pensar a Educação Pensar o Brasil é veiculado semanalmente, ao vivo, toda segunda feira, das $20 \mathrm{~h}$ às $22 \mathrm{~h}$. Estamos no ar, ininterruptamente, desde o dia 04 de setembro do ano de 2007, contando com a realização, até este momento, de mais de 200 programas. Entendemos estar contribuindo para o incentivo e o desenvolvimento dos conceitos de educação; cidadania; respeito à família, aos idosos, professores e entre os alunos. Quando necessário, por meio de divulgações diversas, nos envolvemos em auxiliar entidades assistenciais e filantrópicas em suas campanhas beneficentes e de amparo aos necessitados. Em conjunto, apoiamos a promoção e a divulgação de dados, informações e trabalhos científicos; atividades educacionais; culturais; de pesquisa e de extensão.

Procuramos veicular entrevistas, rodas de discussão e outros meios de expor e propagar o desenvolvimento da educação, das culturas regionais e estimular o respeito entre pessoas e instituições. O rádio, um veículo de comunicação presente em quase todos os lares brasileiros, e recentemente em qualquer parte do planeta Terra, devido à portabilidade da Internet, se torna uma companhia onipresente, sem exigir atenção absoluta, gerando acessibilidade de informação também a analfabetos e a deficientes visuais.

Com uma transmissão intercalada por músicas, criteriosamente selecionadas e adequadamente programadas, objetivamos estimular a melhoria qualitativa da audiência promovendo o conhecimento sobre origens, contextos e gêneros musicais, e também a importância dos compositores, suas obras e respectivas épocas de produção e veiculação.

SANTOS, Hercules P. A extensão universitária promovendo reflexões sobre as transformações na educação pública: ações do Programa Pensar a Educação, Pensar o Brasil - 1822-2022. Extensão em Foco, Curitiba: Ed. da UFPR, nr.9, jan/jun 2014, p.130145. ISSN 2358-7180. 
Expandindo nossas ações, a partir do ano de 2009, nosso programa de Rádio passou a contar com uma retransmissão realizada pela Rádio da Universidade Estadual de Maringá, no Paraná. Recentemente, no ano de 2010, iniciamos transmissões de alguns programas de rádio, ao vivo, diretamente de Escolas Públicas de Belo Horizonte. Nossa intenção, com este esforço, se resume no propósito de criar condições para que as escolas públicas de Belo Horizonte possam divulgar as suas práticas e experiências inovadoras no campo da educação básica. Em conjunto a isto, desmitificar um distanciamento construído culturalmente entre a universidade e a educação de base, demonstrando a articulação de ações e relacionando conhecimentos entre os atores participantes da comunidade acadêmica e o público escolar em geral. Já foram realizados até o momento nove programas transmitidos de escolas públicas.

\section{Mídias do Pensar}

A Internet é o suporte de comunicação que assumiu o patamar mais utilizado pela maioria das pessoas. Trata-se de um repositório de incontáveis páginas de informação encontradas nos mais diversos idiomas e provenientes de todas as partes do mundo. Desta forma, não poderíamos deixar de encampar esta poderosa ferramenta de informação. O quarto projeto integrado ao nosso programa é a manutenção de um website ${ }^{7}$ e de redes sociais virtuais.

Entendemos que se trata de uma forma de possibilitar fundamental aproximação com diversos tipos de público, provenientes de todos os lugares. Consideramos se tratar de uma importante plataforma onde procuramos disponibilizar textos sobre educação, informações sobre as atividades do projeto, agenda dos Seminários Anuais, sugestões de leitura e ainda, uma das seções mais importantes que nos é possibilitada por este advento midiático, o arquivo de áudio do nosso website contendo, na integra, todos os Programas de Rádio já veiculados pela nossa equipe via Rádio UFMG Educativa, 104,5 FM.

${ }^{7}$ Cf.: <http://www.fae.ufmg.br/pensareducacao>.

SANTOS, Hercules P. A extensão universitária promovendo reflexões sobre as transformações na educação pública: ações do Programa Pensar a Educação, Pensar o Brasil - 1822-2022. Extensão em Foco, Curitiba: Ed. da UFPR, nr.9, jan/jun 2014, p.130145. ISSN 2358-7180. 
Queremos que o conteúdo dessas gravações radiofônicas fique disponibilizado e venha a ser amplamente utilizado como fonte de pesquisa, e no mesmo patamar de importância, permitir o uso deste áudio em salas de aula, dos diversos níveis de ensino, a qualquer momento ou época, como forma de aproximar o aluno dos conteúdos por nós discutidos.

Almejamos que os professores realizem um planejamento geral de utilização deste rico material, inserindo-o no conjunto de suas atividades didáticas, claro que, possuindo coerência com os objetivos e conteúdos trabalhados em suas salas de aula. Ao se realizar uma audição dirigida dos programas radiofônicos, deve-se levar em consideração uma leitura crítica sobre estes conteúdos. A condição do professor, neste ponto, deve ser a de mediador da análise perante os seus alunos. Utilizar em sala de aula gravações radiofônicas, como definem os Parâmetros Curriculares Nacionais, "favorece para o desenvolvimento de competências e habilidades que possibilitam a compreensão da lógica da realidade além da construção do conhecimento" (2006, p. 74).

Ainda tratando dos conteúdos disponibilizados por nós na Internet, procuramos nos beneficiar do advento da Internet 2.0, cuja principal característica é a de possibilitar a interação de grupos e pessoas entre si. Como pressupõem alguns autores, caminhamos para deixar de ter um espaço virtual correspondendo a uma coleção de websites de consulta à informação para a existência de uma plataforma inteligente da qual seus utilizadores finais podem, em simultâneo, ser consumidores e fornecedores de informação. Os websites vêm sendo considerados por alguns especialistas como modelos tradicionais de se formatar conteúdos para a Internet, trabalhando basicamente em uma dimensão informacional. Diante do iminente surgimento deste novo contexto tecnológico os internautas interessados nas ações do nosso programa podem contar também com espaços virtuais, onde conteúdos podem ser geridos de forma colaborativa com a possibilidade de se incluir os comentários de outros leitores. Desta forma, dentro do quarto projeto integrado às nossas ações, convidamos o nosso público para realizar uma interação mais dinâmica, virtualmente, por intermédio de algumas das inúmeras redes sociais virtuais transformações na educação pública: ações do Programa Pensar a Educação, Pensar o Brasil - 1822-2022. Extensão em Foco, Curitiba: Ed. da UFPR, nr.9, jan/jun 2014, p.130145. ISSN 2358-7180. 
hoje existentes: Facebook, Orkut e Twitter. Para visitá-las, você encontrará os endereços disponibilizados na página principal de nosso website.

Buscamos nos beneficiar das potencialidades destes recentes dispositivos de informação e comunicação a partir de novos padrões de compartilhamento, preservação e disseminação da informação de interesse público. Com as redes sociais virtuais, compreendidas como um conjunto de atores conectados por relações de amizades, trabalho ou troca de informação, ampliam-se imensamente as possibilidades de interconexão entre os sujeitos na web, propiciando inúmeras complexidades à participação social.

\section{Considerações finais}

Com as ações aqui relatadas, desenvolvidas de forma presencial e por meio de diversas mídias (impressa, digital e radiofônica), estamos em busca de democratizar o acesso ao debate educacional, às pesquisas e ao conhecimento, difundindo e ampliando o número de pessoas interessadas em pensar e discutir a Educação Pública no Brasil. O conteúdo desenvolvido pelo programa Pensar a Educação Pensar o Brasil 1822-2022 é extremamente amplo. Por isto, acreditamos que o modo como este conteúdo é disseminado deve ser variado.

Nossos objetivos específicos estão em desenvolver, por meio deste programa, um conjunto articulado de projetos de extensão, de ensino e de pesquisa, possibilitando a divulgação e o estímulo à criação de reflexões, mas também de conhecimentos científicos sobre a escola pública. Um diálogo permanente com os sujeitos que a constroem no cotidiano, notadamente os educadores, estudantes e a sociedade em geral, tornando proveitosa a relação universidade/comunidade com o conhecimento científico e interagindo com os demais saberes da população. Trata-se de um diálogo permanente, objetivando produzir conhecimento, e se apropriar deste para a resolução de temas e problemas concretos.

Atuar com outros públicos e vivenciar outras dinâmicas, a partir da extensão universitária, possibilita levar para dentro da sala de aula atitudes e ações capazes de criar laços afetivos e cognitivos com o conhecimento e com 
os conteúdos curriculares; isto, seja por parte dos professores recentes ou há considerável tempo em exercício, seja por parte dos alunos em processo de formação, sendo todos estes o público alvo do nosso Programa.

A Extensão apresenta olhares não percebidos dentro da sala de aula. Sair da sala de aula é introduzir-se em outras arenas, é perceber que a visibilidade do educador/educando é edificada em uma lenta e longa construção. É propiciar um processo educacional, científico e cultural articulando o ensino e a pesquisa, permitindo uma relação transformadora entre a universidade e a sociedade. Pretendemos gerar neste âmbito, de forma permanente e contínua, um ambiente que represente o caráter indissociável da Extensão, do Ensino e da Pesquisa.

\section{REFERÊNCIAS}

ALMEIDA, Aelson Silva de. A contribuição da extensão universitária para o desenvolvimento de Tecnologias Sociais. Rede de Tecnologia Social (RTS), 2010. Disponível em: <http://www.rts.org.br/artigos/artigos_-_2009/acontribuicao-da-extensao-universitaria-para-o-desenvolvimento-de-tecnologiassociais>. Acesso em: 26/01/2012.

CALABRE, Lia. A era do rádio. 2. ed. Rio de Janeiro: Jorge Zahar, 2004.

CARVALHO, Isabel Cristina Moura. Educação ambiental: a formação do sujeito ecológico. São Paulo: Cortez, 2004. 256 p.

CARVALHO, Marta Maria Chagas de. Educação e política nos anos 20: a desilusão com a República e o entusiasmo pela educação. In: LORENZO, Helena Carvalho; COSTA, Wilma Peres da (Org.). A Década de 1920 e as origens do Brasil moderno. 1. reimpressão. São Paulo: Editora da UNESP/FAPESP, 1997.

CHARTIER, R. A história cultural: Entre práticas e representações. Lisboa: Difel, 1990.

FARIA FILHO, Luciano Mendes de. Escola pública de qualidade: quanto queremos pagar por isto? SBPC: JC e-mail 4416, de 13 de janeiro de 2012. Disponível em: <http://www.jornaldaciencia.org.br/Detalhe.jsp?id=80745>. Acesso em: 25/01/2012.

INÁCIO, Marcilaine Soares. Políticos, literatos, professoras, intelectuais: o debate público sobre a educação em Minas Gerais. Belo Horizonte: Mazza Edições, c2009.

FÓRUM DE PRÓ-REITORES DE EXTENSÃO DAS UNIVERSIDADES PÚBLICAS BRASILEIRAS. Plano Nacional de Extensão Universitária. Rio de

SANTOS, Hercules P. A extensão universitária promovendo reflexões sobre as transformações na educação pública: ações do Programa Pensar a Educação, Pensar o Brasil - 1822-2022. Extensão em Foco, Curitiba: Ed. da UFPR, nr.9, jan/jun 2014, p.130145. ISSN 2358-7180. 
Janeiro: Forproex, 2001. Disponível em: <www.renex.org.br>. Acesso em: 26/01/2012.

MOURA, Maria Aparecida (Org.). Cultura informacional e liderança comunitária: concepções e práticas. Belo Horizonte: UFMG/PROEX, 2011.

ORTRIWANO, Gisela S. A informação no rádio: os grupos de poder e a determinação dos conteúdos. 2. ed. São Paulo: Summus, 1985.

PARÂMETROS CURRICULARES NACIONAIS. Orientações curriculares para o Ensino Médio: ciências humanas e suas tecnologias. Brasília: Secretaria de Educação, 2006. v. 3.

PENSAR A EDUCAÇÃO. Projeto Pensar a Educação, Pensar o Brasil - 18222022. Projeto original, 2007. Disponível em:

$<$ http://www.pensaraeducacao.com.br/novo/ images/pensar/projeto.pdf>.

Acesso em: 03/01/2012.

PRADO PIMENTEL, Fábio. O Rádio Educativo no Brasil, uma visão histórica. Rio de Janeiro: Soarmec, 2004. $92 \mathrm{p}$.

REVISTA INTERATIVA. Revista do Centro de Apoio a Educação a Distância (CAED) da Universidade Federal de Minas Gerais (UFMG), v. 1, n. 1, dez. 2009. Belo Horizonte: CAED, 2009.

VAGO, Tarcísio Mauro; HAMDAN, Juliana Cesário; INÁCIO, Marcilaine Soares; SANTOS, Hercules Pimenta dos. Intelectuais e escola pública no Brasil: séculos XIX e XX. Belo Horizonte: Mazza Edições, 2009.

XAVIER, Maria do Carmo (Org.). Clássicos da educação brasileira, v. 1. Belo Horizonte: Mazza Edições, 2010.

. HAMDAN, Juliana Cesário (Org.). Clássicos da educação brasileira, v. 2. Belo Horizonte: Mazza Edições, 2011.

UNIVERSIDADE DO ESTADO DE SANTA CATARINA. Pró-Reitoria Comunitária. Coordenação de Extensão. Proposta de Sistematização das Áreas Temáticas. Florianópolis, 2000.

SANTOS, Hercules P. A extensão universitária promovendo reflexões sobre as transformações na educação pública: ações do Programa Pensar a Educação, Pensar o Brasil - 1822-2022. Extensão em Foco, Curitiba: Ed. da UFPR, nr.9, jan/jun 2014, p.130145. ISSN 2358-7180. 